\title{
Dietary supplementation with Lovaza and krill oil shortens the life span of long-lived F1 mice
}

\author{
Stephen R. Spindler • Patricia L. Mote • \\ James M. Flegal
}

Received: 3 August 2013 / Accepted: 21 April 2014 / Published online: 10 May 2014

(C) The Author(s) 2014. This article is published with open access at Springerlink.com

\begin{abstract}
Marine oils rich in $\omega-3$ polyunsaturated fatty acids have been recommended as a preventive treatment for patients at risk for cardiovascular diseases. These oils also are the third most consumed dietary supplement in the USA. However, evidence for their health benefits is equivocal. We tested the daily, isocaloric administration of krill oil ( $1.17 \mathrm{~g}$ oil $/ \mathrm{kg}$ diet $)$ and Lovaza (Omacor; $4.40 \mathrm{~g} / \mathrm{kg}$ diet), a pharmaceutical grade fish oil, beginning at 12 months of age, on the life span and mortality-related pathologies of long-lived, male, $\mathrm{B} 6 \mathrm{C} 3 \mathrm{~F} 1$ mice. The oils were incorporated into the chemically defined American Institute of Nutrition (AIN)-93 M diet. An equivalent volume of soybean oil was removed. Krill oil was $3 \%$ and Lovaza $11 \%$ of the oil in the diets. When their effects were analyzed together, the marine oils significantly shortened life span by $6.6 \%(P=0.0321$; log-rank test $)$ relative to controls. Individually, Lovaza and krill oil non-significantly shortened median life span by 9.8 and $4.7 \%$, respectively. Lovaza increased the number of enlarged seminal vesicles (7.1-fold). Lovaza and krill oil significantly
\end{abstract}

\footnotetext{
S. R. Spindler $(\bowtie) \cdot$ P. L. Mote

Department of Biochemistry, University of California at Riverside, Riverside, CA 92521, USA

e-mail: spindler@ucr.edu

P. L. Mote

e-mail: mote@ucr.edu

J. M. Flegal

Department of Statistics, University of California at

Riverside, Riverside, CA 92521, USA

e-mail: james.flegal@ucr.edu
}

increased lung tumors (4.1- and 8.2-fold) and hemorrhagic diathesis (3.9- and 3.1-fold). Analysis of serum from treated mice found that Lovaza slightly increased blood urea nitrogen, while krill oil modestly increased bilirubin, triglycerides, and blood glucose levels. Taken together, the results do not support the idea that the consumption of isolated $\omega-3$ fatty acid-rich oils will increase the life span or health of initially healthy individuals.

Keywords $\omega-3$ Fatty acids $\cdot$ Lovaza $\cdot$ Krill oil $\cdot$ Marine oil $\cdot$ Mice $\cdot$ Life span $\cdot$ Longevity

\section{Introduction}

Isolated marine oils such as fish oil and krill oil are the third most popular dietary supplement in the USA (Hersher 2012). They are thought to produce positive health outcomes because they contain high concentrations of two major n-3-long-chain, polyunsaturated fatty acids (PUFAs; $\omega-3$ fatty acids): eicosapentaenoic acid (EPA; 20:5n-3) and docosahexaenoic acid (DHA; 22:6n-3) (reviewed in Kar 2011; Rizos et al. 2012). Elevated dietary intakes of EPA and DHA can reduce hyperlipidemia in mice (Ruzickova et al. 2004), rats (Rustan et al. 1992), and humans (Mozaffarian and $\mathrm{Wu}$ 2012). Marine oils may reduce triglyceride levels, arrhythmias, platelet aggregation, and blood pressure (reviewed in Kar 2011; Rizos et al. 2012). One recent meta-analysis suggested that the consumption of fish and marine n-3 polyunsaturated fatty acids may reduce 
the risk of breast cancer (Zheng et al. 2013), while another meta-analysis found no change in overall mortality with omega-3 fatty acid consumption (Zhang et al. 2014). In 2004, a concentrated and highly purified fish oil, trade named Lovaza in the USA and Omacor in Europe (Kar 2011), was approved as a drug by the US Food and Drug Administration for the treatment of hyperlipidemia. A number of European regulatory agencies also approved the use of marine PUFAs for reducing cardiovascular risk factors (Rizos et al. 2012).

Despite these approvals and the positive effects on some cardiovascular risk factors, randomized clinical trials have found mixed results regarding the benefits of marine PUFAs for the prevention of adverse cardiovascular events (Marchioli et al. 2002; Yokoyama et al. 2007; Tavazzi et al. 2008; Kromhout et al. 2010; ORIGIN Trial Investigators et al. 2012). A recent meta-analysis of 20 studies and 68,680 patients found no association of PUFA supplementation with lower risk of all-cause mortality, cardiac death, sudden death, myocardial infarction, or stroke based on relative or absolute measures of association (Rizos et al. 2012). Consistent with these results, another meta-analysis found insufficient evidence for a secondary preventive effect of $\omega-3$ fatty acid supplements against overall cardiovascular events among patients with a history of cardiovascular disease (Kwak et al. 2012).

The consumption of dietary marine oils may have adverse consequences. A fish oil-containing diet appears to reduce immune responsiveness to Helicobacter hepaticus infection, exacerbating a mouse model of inflammatory colitis and increasing colon cancer risk (Woodworth et al. 2010). Increased serum aspartate aminotransferase and alanine aminotransferase activity, which can be evidence of liver toxicity, are adverse reactions reported in clinical studies of Lovaza (GlaxoSmithKline 2013). Hemorrhagic diathesis also is a postmarketing adverse reaction observed with Lovaza (GlaxoSmithKline 2013). Evidence of increased prostate cancer risk among men with high blood concentrations of long-chain $\omega-3$ PUFAs was reported recently (Bassett et al. 2013; Brasky et al. 2013).

Because of the complex and somewhat paradoxical nature of the results summarized above, we investigated the effects of both Lovaza and food grade krill oil on life span and mortality-related pathology, two key healthrelated outcomes. We utilized long-lived, male F1 hybrid mice supplemented with krill oil or Lovaza beginning at 12 months of age. The effects of the compounds on food consumption, body weight, and mortalityassociated outcomes were determined throughout the study period.

\section{Results}

Life span Male C3B6F1 mice were supplemented beginning at 12 months of age with food containing krill oil or Lovaza. The dosages given and the rationale for them are discussed below. When the effects of the marine oils on longevity were analyzed together using the Mantel-Cox log-rank test, they significantly decreased life span by $6.6 \%(P=0.0321)$. Individually, Lovaza and krill oil non-significantly shortened mean life span by approximately 9.8 and $4.7 \%$, respectively (Fig. 1). These data probably were not significant individually because of sample size.

These studies were a part of a larger study in which one control group of 297 mice and 58 treatment groups of 36 mice each were used to screen for the effects of different compounds on life span (e.g., Spindler et al. 2013a, b). Other of these treatments increased life span, although most had no effect. For example, treatment of the mice with $\beta$-adrenergic receptor blockers or $40 \%$ caloric restriction (CR) produced a significant 8.4 and $23 \%$ increase in life span (Spindler et al. 2013b). In contrast, other compounds produced no effect on life

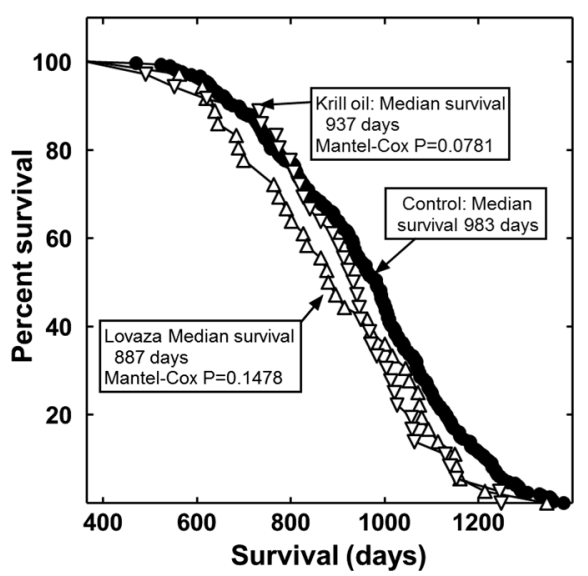

Fig. 1 Life span of mice fed a control diet or a diet supplemented with Lovaza or krill oil. Shown are the life spans of the control (filled circles), krill oil-treated mice (downward-pointing triangles), and Lovaza-treated mice (upward-pointing triangles). The percentage of mice remaining alive at the end of each time period shown is plotted. The controls began with 297 mice and the treatment groups with 36 mice each. The graph begins at 365 days of age, when treatments were started 
span (e.g., Spindler et al. 2013a, 2014). The sample sizes in this study are similar to those required for a Weibull survival analyses with a $75 \%$ probability of detecting a $10 \%$ increase in mean life span with a $1 \%(\beta \leq 0.01)$ probability of a false positive. The Weibull survival analysis is more stringent than the log-rank test (Jeske et al. 2014).

Rationale for dosages Krill oil was administered at $1.17 \mathrm{~g}$ oil $/ \mathrm{kg}$ diet, which is $\sim 124 \mathrm{mg} / \mathrm{kg}$ body weight per day $(\mathrm{mg} / \mathrm{kg}$ bw/day), or approximately $3 \%$ of the oil in the diet. The calculation assumes a body weight of $39 \mathrm{~g}$, which is approximately the median weight of the mice during the treatments (Fig. 2). Lovaza was administered at $4.40 \mathrm{~g} / \mathrm{kg}$ diet, which is $\sim 467 \mathrm{mg} / \mathrm{kg} \mathrm{bw} /$ day, or approximately $11 \%$ of the oil in the diet. An equivalent volume of soybean oil was removed from each diet to compensate calorically for the additions. The American Institute of Nutrition (AIN)-93 M diet contains $40 \mathrm{~g}$ soybean oil per $\mathrm{kg}$ diet, which provides only small amounts of EPA or DHA from the inefficient metabolic conversion of other fatty acids in the oil (Reeves et al. 1993; De Caterina 2011). The krill oil brand used is $23 \%$ EPA and $6.5 \%$ DHA by weight, while Lovaza is $55 \%$

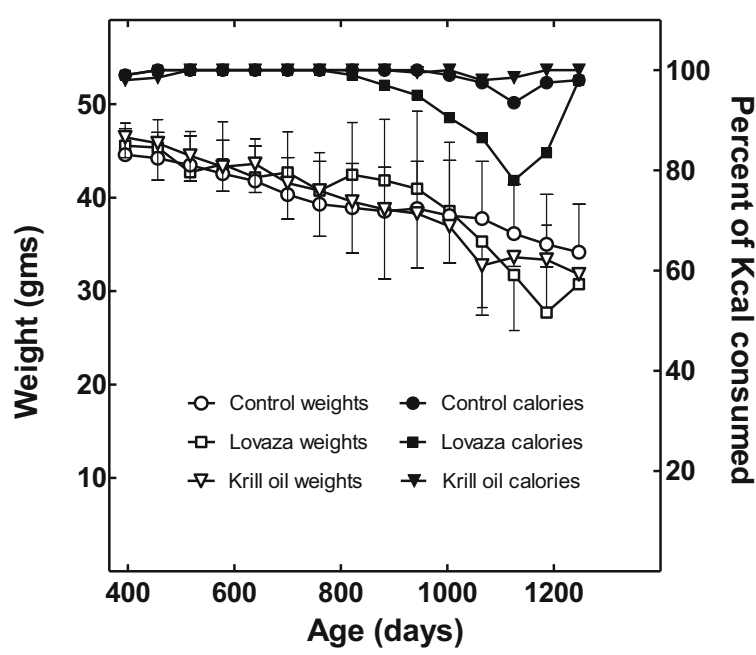

Fig. 2 Body weights and food consumption of the mice. The symbols are as labeled in the figure. The notation Percent of Kcal consumed refers to the percent of the food eaten with respect to the amount presented to the mice in each treatment group per mouse during the preceding 30 days with respect to the amount consumed by the control mice during the same period. For the weights of the mice, the median weight plus or minus the standard deviation is shown. The differences between the weights of the groups were not significant, as judged using a linear mixed effects model as described previously (Spindler et al. 2013a)
EPA and $45 \%$ DHA by weight. We could not find a literature describing the use of Lovaza in mice. The recommended dose in humans is $4.0 \mathrm{~g} /$ day, which would provide $50 \mathrm{mg} / \mathrm{kg}$ bw/day for an $80-\mathrm{kg}$ adult. The crossspecies scaling factors used to adjust dosages between animals and humans suggest that mice should receive 8 to 12 times the effective human dosage of a drug to account for species-specific pharmacodynamic and pharmacokinetic differences (reviewed in Spindler 2012). The Lovaza dose used here is approximately 9.3 times the recommended human dosage per kilogram body weight. The krill oil dosage is modest in comparison to the dosages used in mouse studies to demonstrate a beneficial effect on serum and hepatic cholesterol and triglyceride levels (Vigerust et al. 2012; Tandy et al. 2009). For example, tumor necrosis factor alphatransgenic mice fed a high-fat diet containing $5.8 \%$ krill oil (approximately five times the dosage used here) had lower plasma levels of triacylglycerol and cholesterol and higher levels of hepatic mitochondrial and peroxisomal fatty acid $\beta$-oxidation and carnitine turnover (Vigerust et al. 2012). High fat-fed mice receiving krill oil at $12.5 \mathrm{~g} / \mathrm{kg}$ diet (approximately 10 times that used here) had reduced hepatomegaly, hepatic steatosis, triacylglycerols, and cholesterol (Tandy et al. 2009).

Food consumption and body weight To determine the possible effects of the compounds on food intake and body weight, the mice were fed a known number of calories each day, and both parameters were quantified throughout the study (Fig. 2). As is typical of meal-fed $\mathrm{B} 6 \mathrm{C} 3 \mathrm{~F} 1$ mice, all the mice began to lose weight beginning at about 12 months of age, even though they were eating near ad libitum levels of calories (e.g., Spindler et al. 2013a, b; Martin-Montalvo et al. 2013). As in our previous studies, the mean weight estimates became increasingly unstable as days on diet increased, because the number of mice diminished with time (Spindler et al. 2013a, b). Thus, neither the Lovaza nor the krill oil diet produced a consistent treatment effect on body weight (Fig. 2). Anomalously, at 1,125 days of age, the Lovaza diet-fed mice consumed only $78 \%$ of the food offered (Fig. 2). However, only five of the mice remained at this time. Three of these mice died in the ensuing month, and the remaining mice consumed a more "normal" amount of food.

Necropsies Necropsy results are shown in Tables 1 and 2. The necropsied control mice were randomly chosen by 
age at death to approximate the age distribution of the entire cohort. Both Lovaza and krill oil consumption significantly increased the number of mice with peritoneal hemorrhagic diathesis (bleeding into the peritoneum; Table 1). The increase was 3.9-fold for Lovaza and 3.1fold for krill oil. As mentioned in the "Introduction," hemorrhagic diathesis is a postmarketing adverse reaction which has been reported for Lovaza by GlaxoSmithKline (2013). We were unable to determine the frequency or severity of this outcome from the information available. In our study, Lovaza treatment also produced a significant increase in the number of enlarged seminal vesicles (7.1-fold; Table 1). There was a $52 \%$ reduction in the median liver tumor mass in the Lovaza-treated mice (Table 2). This size reduction may not have been the result of their shortened life spans, since a similar effect was not found for the krill oil-treated mice (e.g., Dhahbi et al. 2004; Spindler 2005). Lovaza and krill oil treatment produced a significant 4.1- and 8.2-fold increase, respectively, in the number of lung tumors (Table 1).
Thus, marine oil consumption was associated with an increase in the onset, incidence, or severity of multiple adverse health outcomes.

Serum tests To determine whether the decrease in life span was related to drug-induced toxicity, serum samples were analyzed from mice of the same sex and strain fed the Lovaza or krill oil diets (Tables 3 and 4). Most of the parameters measured were not changed significantly by the treatments, suggesting that the oils were not overtly toxic to the liver, muscle, kidney, or other organ systems. Lovaza produced a modest reduction in blood urea nitrogen (Table 3). However, this change was quantitatively modest, not found in the krill oil diet-treated group, and is therefore of uncertain significance. The Lovaza-treated mice did have unkempt hair coats, which can be a symptom of generalized illness.

The krill oil-treated group showed limited signs of toxicity. Their bilirubin, triglyceride, and glucose levels were modestly elevated (Table 4). Elevation of these

Table 1 Necropsy results from the mouse longevity studies shown in Fig. 1

\begin{tabular}{|c|c|c|c|c|c|c|c|c|c|}
\hline \multirow[t]{3}{*}{ Organ } & \multirow[t]{3}{*}{ Pathology } & \multicolumn{8}{|c|}{ Diet treatment $(n)$} \\
\hline & & \multicolumn{2}{|c|}{ Control $(n=36)^{\mathrm{a}}$} & \multicolumn{3}{|c|}{ Lovaza $(n=35)$} & \multicolumn{3}{|c|}{ Krill oil $(n=35)$} \\
\hline & & No. ${ }^{b}$ & $\%^{\mathrm{c}}$ & No. & $\%$ & $P$ value ${ }^{\mathrm{d}}$ & No. & $\%$ & $P$ value \\
\hline Spleen & Enlarged/tumorous & 23 & 63.9 & 23 & 65.7 & 1.0000 & 20 & 57.1 & 0.6312 \\
\hline \multirow[t]{3}{*}{ Liver } & Tumor & 11 & 30.6 & 17 & 48.6 & 0.1488 & 13 & 37.1 & 0.6210 \\
\hline & Enlarged/fatty liver & 1 & 2.8 & 1 & 2.9 & 1.0000 & 3 & 8.6 & 0.3570 \\
\hline & Hemangioma & 4 & 11.1 & 1 & 2.9 & 0.3570 & 0 & 0.0 & 0.1145 \\
\hline Intestinal & Tumor & 5 & 13.9 & 8 & 22.9 & 0.3723 & 4 & 11.4 & 1.0000 \\
\hline Lung & Tumor & 2 & 5.6 & 8 & 22.9 & 0.0457 & 16 & 45.7 & $9.769 e-05$ \\
\hline Penis & Necrosed/inflamed & 0 & 0 & 2 & 5.7 & 0.2394 & 0 & 0.0 & 1.0000 \\
\hline Seminal vesicles & Enlarged & 1 & 2.8 & 7 & 20.0 & 0.0278 & 3 & 8.6 & 0.3570 \\
\hline Bladder & Distended & 6 & 16.7 & 5 & 14.3 & 1.0000 & 2 & 5.7 & 0.2603 \\
\hline Kidneys & Enlarged/tumorous & 3 & 8.3 & 0 & 0.0 & 0.2394 & 2 & 5.7 & 1.0000 \\
\hline Thymus & Enlarged & 1 & 2.8 & 3 & 8.6 & 0.3570 & 4 & 11.4 & 0.1987 \\
\hline Skin/abdominal cavity & Fibroma & 1 & 2.8 & 1 & 2.9 & 1.0000 & 2 & 5.7 & 0.6142 \\
\hline Peritoneal cavity & Hemorrhage & 4 & 11.1 & 15 & 42.9 & 0.0032 & 12 & 34.3 & 0.0246 \\
\hline
\end{tabular}

\footnotetext{
${ }^{a}$ Number of necropsied mice in each treatment group. The necropsied control mice were chosen randomly from among the mice of appropriate ages for approximating the age distribution of the marine oil-treated mice. One mouse from each treatment group was cannibalized and could not be necropsied

${ }^{\mathrm{b}}$ Number of necropsied mice in each treatment group with the indicated pathologies

${ }^{\mathrm{c}}$ Percent of the necropsied mice in the treatment group with the indicated pathologies

${ }^{\mathrm{d}}$ Fisher's exact test was utilized to investigate the association between the pathologies and treatment groups. The values that were significantly different or near significance are in italics. The $P$ values are two-sided
} 
Table 2 Liver tumor mass of the mice shown in Fig. 1

${ }^{\mathrm{a} O n e} \mathrm{~cm}^{3}=1 \mathrm{~g}$

${ }^{\mathrm{b}}$ Calculated using the

Mann-Whitney $U$ test

\begin{tabular}{llll}
\hline & $\begin{array}{l}\text { Control }(n=36) \\
\text { Mass }(\mathrm{g})^{\mathrm{a}}\end{array}$ & $\begin{array}{l}\text { Lovaza }(n=35) \\
\text { Mass }(\mathrm{g})\end{array}$ & $\begin{array}{l}\text { Krill oil }(n=35) \\
\text { Mass }(\mathrm{g})\end{array}$ \\
\hline Median mass of each tumor & 0.54 & $0.28(P=0.033)^{\mathrm{b}}$ & $\begin{array}{l}0.61(P=0.231) \\
1.3\end{array}$ \\
Tumor mass/number of mice with tumors & 1.1 & 1.1 & 1.3 \\
\hline
\end{tabular}

parameters can be a sign of liver dysfunction. The Lovazatreated mice also had numerically elevated triglycerides, although this change did not reach significance. High fatfed mice receiving krill oil at $12.5 \mathrm{~g} / \mathrm{kg}$ diet (approximately 10 times that used here) had reduced triacylglycerol and cholesterol levels (Tandy et al. 2009). However, we found an opposite effect on triglycerides for mice consuming the AIN-recommended levels of fat and carbohydrate (AIN-93 M diet; Table 3) (Reeves et al. 1993).

\section{Discussion}

The work presented here shows for the first time that the consumption of either commercial or pharmaceutical grade marine oils can have adverse health effects. The krill oil dosage we used is below that commonly used for the treatment of mice in the scientific literature. In the case of Lovaza, the recommended human dose was scaled up according to accepted cross-species scaling factors. Both oils were present as a relatively small fraction of the total oil in the diet.

Of the pathologies found upon necropsy, hemorrhagic diathesis seems likely to be responsible for a significant proportion of the early mortality of the treated mice. It was substantially and significantly elevated in both the Lovaza- and krill oil-treated mice (Table 1). It is a probable consequence of the anticoagulant effects of dietary marine oils observed in both rodents and humans (Calder and Yaqoob 2012; Sano et al. 2003). The increase in lung tumors in the Lovaza- and krill oil-treated mice also may have contributed to their early mortality. Recent evidence suggests that a diet containing fish oil promotes tumor growth by suppressing $\mathrm{CD}^{+}$activation in mice (Xia et al. 2014). Thus, the anti-inflammatory effects of marine oils may have negative as well as positive consequences. A fish oil-containing diet significantly decreased the number of $\mathrm{CD}^{+} \mathrm{T}$ cells in the lungs of influenza virusinfected mice, leading to elevated rates of morbidity and mortality (Schwerbrock et al. 2009).

Serum tests found little evidence for a significant level of toxicity related to marine oil consumption. The increase in total bilirubin, triglycerides, and glucose in the krill oil-treated group and blood urea nitrogen in the Lovaza-treated mice is modest and not likely sources of early mortality. Thus, there is little evidence that the detrimental effects of these PUFAs on survival are the result of direct toxic effects of the oils or contamination of
Table 3 Serum tests for Lovaza diet-fed mice. Six treated and six control 19-month-old mice of the same sex and strain used in the life span studies were fed the Lovaza supplemented diet for 16 weeks prior to bleeding by heart puncture

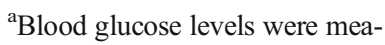
sured with the FreeStyle Lite Blood Glucose Monitoring System (Abbot Laboratories). The other blood tests were performed by the Comparative Pathology Laboratory, University of California, Davis

${ }^{\mathrm{b}}$ Calculated using two-sample $t$ tests

\begin{tabular}{llll}
\hline Test $^{\mathrm{a}}$ & Control & Lovaza & $P$ value $^{\mathrm{b}}$ \\
\hline Alanine aminotransferase (U/L) & $30.3 \pm 11.9$ & $28.1 \pm 7.5$ & 0.720 \\
Aspartate aminotransferase (U/L) & $157.9 \pm 36.3$ & $112.4 \pm 44.3$ & 0.083 \\
Alkaline phosphatase (U/L) & $60.0 \pm 10.3$ & $56.3 \pm 14.3$ & 0.624 \\
Blood urea nitrogen (mg/dL) & $19.1 \pm 3.1$ & $14.5 \pm 2.7$ & 0.021 \\
Cholesterol (mg/dL) & $182.5 \pm 21.1$ & $163.9 \pm 31.5$ & 0.263 \\
Creatinine (mg/dL) & $0.069 \pm 0.012$ & $0.076 \pm 0.023$ & 0.535 \\
High-density lipoprotein (mg/dL) & $196.4 \pm 27.3$ & $173.0 \pm 34.8$ & 0.229 \\
Low-density lipoprotein (mg/dL) & $19.17 \pm 3.86$ & $16.74 \pm 5.98$ & 0.428 \\
Total bilirubin (mg/dL) & $0.093 \pm 0.025$ & $0.123 \pm 0.045$ & 0.188 \\
Total protein (g/dL) & $6.27 \pm 0.38$ & $5.94 \pm 0.50$ & 0.234 \\
Triglyceride (mg/dL) & $69.5 \pm 37.0$ & $112.1 \pm 99.2$ & 0.362 \\
Glucose, non-fasting (mg/dL) & $176.3 \pm 24.1$ & $151.3 \pm 26.2$ & 0.120 \\
\hline
\end{tabular}


Table 4 Serum tests for krill oil diet-fed mice. Six treated and six control 16-month-old mice of the same sex and strain used in the life span studies were fed the krill oil supplemented diet for 11 weeks prior to bleeding by heart puncture

${ }^{a}$ Blood glucose levels were measured with the FreeStyle Lite Blood Glucose Monitoring System (Abbot Laboratories). The other blood tests were performed by the Comparative Pathology Laboratory, University of California, Davis

${ }^{\mathrm{b}}$ Calculated using two-sample $t$ tests

\begin{tabular}{llll}
\hline Test $^{\mathrm{a}}$ & Control & Krill oil & $P$ value $^{\mathrm{b}}$ \\
\hline Alanine aminotransferase (U/L) & $45.6 \pm 29.8$ & $29.3 \pm 7.7$ & 0.251 \\
Aspartate aminotransferase (U/L) & $106.8 \pm 31.2$ & $110.7 \pm 17.7$ & 0.798 \\
Alkaline phosphatase (U/L) & $73.1 \pm 15.2$ & $72.9 \pm 9.1$ & 0.982 \\
Blood urea nitrogen (mg/dL) & $18.7 \pm 2.4$ & $19.9 \pm 2.4$ & 0.408 \\
Cholesterol (mg/dL) & $186.4 \pm 43.4$ & $187.7 \pm 34.7$ & 0.957 \\
Creatinine (mg/dL) & $0.052 \pm 0.017$ & $0.055 \pm 0.017$ & 0.817 \\
High-density lipoprotein (mg/dL) & $175.9 \pm 39.4$ & $179.8 \pm 34.4$ & 0.860 \\
Low-density lipoprotein (mg/dL) & $28.1 \pm 14.0$ & $27.8 \pm 10.9$ & 0.963 \\
Total bilirubin (mg/dL) & $0.081 \pm 0.011$ & $0.115 \pm 0.029$ & 0.034 \\
Total protein (g/dL) & $6.40 \pm 0.63$ & $6.44 \pm 0.73$ & 0.921 \\
Triglyceride (mg/dL) & $72.0 \pm 14.8$ & $95.9 \pm 14.8$ & 0.021 \\
Glucose, non-fasting (mg/dL) & $111.3 \pm 33.9$ & $158.0 \pm 23.5$ & 0.024 \\
\hline
\end{tabular}

the oils by the environmental pollutants commonly associated with marine fish, such as methyl mercury, dioxins, or polychlorinated biphenyls (Turunen et al. 2010). Lovaza is a highly purified prescription drug, with very low levels of these toxicants (GlaxoSmithKline 2013).

It is unlikely that the negative effects of these diets on life span were related to the presence of high levels of oxidation products in the oils themselves. The oils were supplied in sealed capsules. These were rapidly opened, combined, and stored sealed in bottles under argon. The bottles were sent to BioServ via expedited shipping. At BioServ, the oils were opened and compounded with the diets, cold pressed into food pellets, and packed in airtight plastic bags. After receipt in the laboratory, the plastic bags of food were stored at $-20{ }^{\circ} \mathrm{C}$. Approximately 1-week aliquot of food was transferred from these bags into airtight Rubbermaid tubs, which were stored at $-20{ }^{\circ} \mathrm{C}$. The plastic tubs were warmed to room temperature each day before opening for feeding and then returned to the freezer.

As discussed in the "Introduction," the evidence for an association between marine oil consumption and better health or survival is equivocal. To the best of our knowledge, there are no long-term human or mouse survival studies performed with either Lovaza or other marine oils using initially healthy subjects. A study with senescenceaccelerated mice found that the long-term oral administration of fish oil decreased life span (Tsuduki et al. 2011). While these results are similar to ours, studies performed in enfeebled mouse models have a limited predictive value for outcomes in healthy subjects (Spindler 2012). For example, among the many compounds reported to extend the life span of enfeebled mice, only one has been shown to extend the life span of healthy mice (Martin-Montalvo et al. 2013; Anisimov et al. 2005a, b).

F1 hybrid mice were utilized for these studies because they are heterozygous for the alleles differing between their parents. They tend to be more robust and longer lived than their inbred parental lines (Spindler and Mote 2007; Spindler 2012). We have shown that their life span is responsive to multiple interventions including CR (Spindler et al. 2013a), $\beta 1$ adrenergic receptor antagonists (Spindler et al. 2013b), and metformin (Martin-Montalvo et al. 2013), suggesting that they are appropriate models for testing potential longevity therapeutics.

\section{Conclusions}

Doses of krill oil and Lovaza consistent with those recommended for human use decreased the life span of healthy mice. Marine oil consumption increased deaths associated with hemorrhagic diathesis and specific tumor types. In light of the current uncertainties regarding the efficacy of purified marine oils in treating human diseases, our results do not support their use to increase health or life span.

\section{Materials and methods}

Mouse husbandry and life span studies The study design and husbandry conditions are described in detail 
elsewhere (Spindler et al. 2013a, b). Briefly, male B6C3F1 mice (Harlan Breeders; Indianapolis) were randomly assigned to treatment groups at 12 months of age and switched to daily feeding with $13.3 \mathrm{kcal} /$ day/mouse of control diet (AIN-93 M, Diet No. F05312; BioServ, Frenchtown, NJ). The control group was composed of 297 mice. Test cohorts of 36 mice were fed control diet supplemented with either krill oil (Neptune Krill Oil, Jarrow) or Lovaza (GlaxoSmithKline) at the dosages indicated in the text. Fifty-six other groups of mice were fed other chemical agents in their diets or were calorically restricted. All mice were fed daily. Food consumption was monitored at the time of feeding, and any uneaten food was noted. Dead mice were stored at $-20{ }^{\circ} \mathrm{C}$ until necropsy. Kaplan-Meier survival curves were compared using the log-rank test implemented in GraphPad Prism 5.01. The probability of detecting a false positive or negative was less than $1 \%$ (Jeske et al. 2014). The statistics were not corrected for multiple testing. The data were not censored. Mice were weighed bimonthly, and the weights recorded. The significance of the differences in weight was determined as described previously (Spindler et al. 2013a). Because the mice were multiply caged, food consumption was determined by totaling the amount eaten by each treatment group during each time period, adjusted for the number of mice in each cage. This number was divided by the amount eaten by the control mice, also adjusted for the number of mice alive per cage.

Acknowledgments The authors thank Ms. Carol Boyd for her help in feeding and monitoring the mice. This work was funded by anonymous donors.

Conflict of interest The funders had no role in study design, data collection or analysis, decision to publish, or preparation of the manuscript. The authors have no competing interests.

Open Access This article is distributed under the terms of the Creative Commons Attribution License which permits any use, distribution, and reproduction in any medium, provided the original author(s) and the source are credited.

\section{References}

Anisimov VN, Berstein LM, Egormin PA, Piskunova TS, Popovich IG, Zabezhinski MA, Kovalenko IG, Poroshina TE, Semenchenko AV, Provinciali M, Re F, Franceschi C (2005a) Effect of metformin on life span and on the development of spontaneous mammary tumors in HER-2/neu transgenic mice. Exp Gerontol 40:685-693

Anisimov VN, Egormin PA, Bershtein LM, Zabezhinskii MA, Piskunova TS, Popovich IG, Semenchenko AV (2005b)
Metformin decelerates aging and development of mammary tumors in HER-2/neu transgenic mice. Bull Exp Biol Med 139:721-723

Bassett JK, Severi G, Hodge AM, Macinnis RJ, Gibson RA, Hopper JL, English DR, Giles GG (2013) Plasma phospholipid fatty acids, dietary fatty acids and prostate cancer risk. Int J Cancer 133:188291. doi:10.1002/ijc.28203

Brasky TM, Darke AK, Song X, Tangen CM, Goodman PJ, Thompson IM, Meyskens FL Jr, Goodman GE, Minasian LM, Parnes HL, Klein EA, Kristal AR (2013) Plasma phospholipid fatty acids and prostate cancer risk in the SELECT trial. J Natl Cancer Inst 105:1132-1141

Calder PC, Yaqoob P (2012) Marine omega-3 fatty acids and coronary heart disease. Curr Opin Cardiol 27:412-419

De Caterina R (2011) n-3 fatty acids in cardiovascular disease. N Engl J Med 364:2439-2450

Dhahbi JM, Kim HJ, Mote PL, Beaver RJ, Spindler SR (2004) Temporal linkage between the phenotypic and genomic responses to caloric restriction. Proc Natl Acad Sci USA 101: 5524-5529

GlaxoSmithKline (2013) GSK medical professional information: adverse reactions. http://www.gsksource.com/gskprm/en/ US/adirect/gskprm?cmd=ProductDetailPage\&product_id= $1336506912652 \&$ featureKey=603462\#section-34084-4

Hersher R (2012) Are drugmakers fishing for a market with prescription omega-3 s? Nat Med 18(1):6

Jeske DR, Flegal J, Spindler SR (2014) Minimum size survival analysis sampling plans for comparing multiple treatment groups to a single control group. Commun Stat Theory Methods 43:9

Kar S (2011) Omacor and omega-3 fatty acids for treatment of coronary artery disease and the pleiotropic effects. Am J Ther 21:56-66

Kromhout D, Giltay EJ, Geleijnse JM (2010) n-3 Fatty acids and cardiovascular events after myocardial infarction. N Engl J Med 363(21):2015-2026

Kwak SM, Myung SK, Lee YJ, Seo HG, Korean Meta-analysis Study Group (2012) Efficacy of omega-3 fatty acid supplements (eicosapentaenoic acid and docosahexaenoic acid) in the secondary prevention of cardiovascular disease: a metaanalysis of randomized, double-blind, placebo-controlled trials. Arch Intern Med 172(9):686-694

Marchioli R, Barzi F, Bomba E, Chieffo C, Di GD, Di MR, Franzosi MG, Geraci E, Levantesi G, Maggioni AP, Mantini L, Marfisi RM, Mastrogiuseppe G, Mininni N, Nicolosi GL, Santini M, Schweiger C, Tavazzi L, Tognoni G, Tucci C, Valagussa F (2002) Early protection against sudden death by $n-3$ polyunsaturated fatty acids after myocardial infarction: time-course analysis of the results of the Gruppo Italiano per lo Studio della Sopravvivenza nell'Infarto Miocardico (GISSI)-Prevenzione. Circulation 105(16):1897-1903

Martin-Montalvo A, Mercken EM, Mitchell SJ, Palacios HH, Mote PL, Scheibye-Knudsen M, Gomes AP, Ward TM, Minor RK, Blouin MJ, Schwab M, Pollak M, Zhang Y, Yu Y, Becker KG, Bohr VA, Ingram DK, Sinclair DA, Wolf NS, Spindler SR, Bernier M, de Cabo R (2013) Metformin improves healthspan and lifespan in mice. Nat Commun 4:2192

Mozaffarian D, Wu JH (2012) (n-3) fatty acids and cardiovascular health: are effects of EPA and DHA shared or complementary? J Nutr 142(3):614S-625S 
ORIGIN Trial Investigators, Bosch J, Gerstein HC, Dagenais GR, Diaz R, Dyal L, Jung H, Maggiono AP, Probstfield J, Ramachandran A, Riddle MC, Ryden LE, Yusuf S (2012) n-3 fatty acids and cardiovascular outcomes in patients with dysglycemia. N Engl J Med 367:309-318

Reeves PG, Nielsen FH, Fahey GC Jr (1993) AIN-93 purified diets for laboratory rodents: final report of the American Institute of Nutrition ad hoc writing committee on the reformulation of the AIN-76A rodent diet. J Nutr 123: 1939-1951

Rizos EC, Ntzani EE, Bika E, Kostapanos MS, Elisaf MS (2012) Association between omega-3 fatty acid supplementation and risk of major cardiovascular disease events: a systematic review and meta-analysis. JAMA 308:1024-1033

Rustan AC, Christiansen EN, Drevon CA (1992) Serum lipids, hepatic glycerolipid metabolism and peroxisomal fatty acid oxidation in rats fed omega- 3 and omega- 6 fatty acids. Biochem J 283(Pt 2):333-339

Ruzickova J, Rossmeisl M, Prazak T, Flachs P, Sponarova J, Veck M, Tvrzicka E, Bryhn M, Kopecky J (2004) Omega3 PUFA of marine origin limit diet-induced obesity in mice by reducing cellularity of adipose tissue. Lipids 39(12):1177-1185

Sano Y, Sato K, Uchida M, Murata M (2003) Blood coagulation and fibrinolysis of rats fed fish oil: reduced coagulation factors especially involved in intrinsic pathway and increased activity of plasminogen activator inhibitor. Biosci Biotechnol Biochem 67:2100-2105

Schwerbrock NM, Karlsson EA, Shi Q, Sheridan PA, Beck MA (2009) Fish oil-fed mice have impaired resistance to influenza infection. J Nutr 139:1588-1594

Spindler SR (2005) Rapid and reversible induction of the longevity, anticancer and genomic effects of caloric restriction. Mech Ageing Dev 126(9):960-966

Spindler SR (2012) Review of the literature and suggestions for the design of rodent survival studies for the identification of compounds that increase health and life span. Age (Dordr) 34:111-120

Spindler SR, Mote PL (2007) Screening candidate longevity therapeutics using gene-expression arrays. Gerontology 53:306321

Spindler SR, Mote PL, Flegal JM, Teter B (2013a) Influence on longevity of blueberry, cinnamon, green and black tea, pomegranate, sesame, curcumin, morin, pycnogenol, quercetin and taxifolin fed isocalorically to long-lived, F1 hybrid mice. Rejuvenation Res 16:143-151

Spindler SR, Mote PL, Li R, Dhahbi JM, Yamakawa A, Flegal JM, Jeske DR, Li R, Lublin AL (2013b) ß1-Adrenergic receptor blockade extends the life span of Drosophila and long-lived mice. Age (Dordr) 35:2099-2109
Spindler SR, Mote PL, Flegal JM (2014) Lifespan effects of simple and complex nutraceutical combinations fed isocalorically to mice. Age (Dordr) 36:705-718

Tandy S, Chung RW, Wat E, Kamili A, Berge K, Griinari M, Cohn JS (2009) Dietary krill oil supplementation reduces hepatic steatosis, glycemia, and hypercholesterolemia in high-fat-fed mice. J Agric Food Chem 57(19):9339-9345

Tavazzi L, Maggioni AP, Marchioli R, Barlera S, Franzosi MG, Latini R, Lucci D, Nicolosi GL, Porcu M, Tognoni G (2008) Effect of n-3 polyunsaturated fatty acids in patients with chronic heart failure (the GISSI-HF trial): a randomised, double-blind, placebo-controlled trial. Lancet 372(9645): $1223-1230$

Tsuduki T, Honma T, Nakagawa K, Ikeda I, Miyazawa T (2011) Long-term intake of fish oil increases oxidative stress and decreases lifespan in senescence-accelerated mice. Nutrition 27:334-337

Turunen AW, Mannisto S, Kiviranta H, Marniemi J, Jula A, Tiittanen P, Suominen-Taipale L, Vartiainen T, Verkasalo PK (2010) Dioxins, polychlorinated biphenyls, methyl mercury and omega-3 polyunsaturated fatty acids as biomarkers of fish consumption. Eur J Clin Nutr 64(3):313-323

Vigerust NF, Bjorndal B, Bohov P, Brattelid T, Svardal A, Berge RK (2012) Krill oil versus fish oil in modulation of inflammation and lipid metabolism in mice transgenic for TNFalpha. Eur J Nutr 52(4):1315-1325

Woodworth HL, McCaskey SJ, Duriancik DM, Clinthorne JF, Langohr IM, Gardner EM, Fenton JI (2010) Dietary fish oil alters $\mathrm{T}$ lymphocyte cell populations and exacerbates disease in a mouse model of inflammatory colitis. Cancer Res 70(20):7960-7969

Xia S, Li X, Cheng L, Han M, Zhang M, Liu X, Xu H, Zhang M, Shao Q, Qi L (2014) Chronic intake of high fish oil diet induces myeloid-derived suppressor cells to promote tumor growth. Cancer Immunol Immunother [Epub ahead of print]

Yokoyama M, Origasa H, Matsuzaki M, Matsuzawa Y, Saito Y, Ishikawa Y, Oikawa S, Sasaki J, Hishida H, Itakura H, Kita T, Kitabatake A, Nakaya N, Sakata T, Shimada K, Shirato K (2007) Effects of eicosapentaenoic acid on major coronary events in hypercholesterolaemic patients (JELIS): a randomised open-label, blinded endpoint analysis. Lancet 369(9567):1090-1098

Zhang YF, Gao HF, Hou AJ, Zhou YH (2014) Effect of omega-3 fatty acid supplementation on cancer incidence, non-vascular death, and total mortality: a meta-analysis of randomized controlled trials. BMC Public Health 14:204

Zheng JS, Hu XJ, Zhao YM, Yang J, Li D (2013) Intake of fish and marine n-3 polyunsaturated fatty acids and risk of breast cancer: meta-analysis of data from 21 independent prospective cohort studies. BMJ 346:f3706. doi:10.1136/bmj.f3706 